\title{
Inspecting Inspection Reports, Does the Type of Restaurant Change the Risk?”
}

\author{
Paul Cseke. ${ }^{1}$, Helen Heacock ${ }^{2}$, Bobby Sidhu ${ }^{3}$, Lorraine McIntyre ${ }^{3}$, Lynn Wilcott ${ }^{3}$ \\ 1. Lead Author, B Tech Student of Health Sciences, British Columbia Institution of Technology, 3700 \\ Willingdon Ave, BC V5G 3H2 \\ 2. Supervisor, School of Health Sciences, British Columbia Institution of Technology, 3700 Willingdon \\ Ave, Burnaby, BC V5G 3H2 \\ 3. Contributor, British Columbia Centre for Disease Control, 655 West $12^{\text {th }}$ Ave, Vancouver, B.C. V5Z \\ 4R4
}

\section{ABSTRACT \\ Background}

An estimated of 4 million Canadians (one in eight people) become ill every year from a food-borne illness (Thomas et al., 2013). The economic and social burdens of these illnesses are vast. As restaurants are a big sector of the food industry, improving their food safety would reduce the risk of food-borne illnesses. Environmental Health Officers (EHOs) are on the front line, educating restaurant operators in order to improve food safety. In Metro Vancouver there are many different types of ethnicities and types of restaurants; this provides a challenge for EHOs to know where to allocate their time and resources.

Methods

The author analyzed 150 Fraser Health inspection reports in the Burnaby, New Westminster and Surrey municipalities. The restaurants fell into three different categories: i) Independently owned ethnic, ii) Independently owned, non-ethnic and iii) chain non-ethnic restaurants. Hazard ratings, number of critical and number of noncritical violations from their latest inspection report were compared. Each violation code was also recorded to identify any infraction trends that exist.

Results

Analysis of the number of critical violations identified ethnic, chain non-ethnic, and independent nonethnic restaurants as not being significantly different $(\mathrm{p}=0.09)$. The number of non-critical violations was different (0.033), with ethnic restaurants having the most. The number of critical violations, when treating each ethnicity as its own category, is however significantly different $(\mathrm{p}=0.044)$ between restaurant types. There was a significant association between hazard rating and restaurant type, with independent ethnic restaurants having the worst hazard rating $(\mathrm{p}=0.017)$.

\section{Conclusion}

The type of ownership (independent vs chain) and the restaurant type were not a factor when looking at number of critical violations that a restaurant commits. Independent ethnic restaurants had a slightly higher mean number of critical violations. Japanese restaurants had the highest number of critical violations out of the three ethnicities studied. These findings suggest a slight disparity in risk to public health between ethnic and non-ethnic restaurants.

\section{INTRODUCTION}

When an individual from the general public enters a restaurant or a food service establishment, they are provided a service and are not responsible for transporting, processing, or cooking the food. This means that the customer is in complete trust that the staff will provide them with safe food. The Health Authorities in Canada use Environmental Health Officers (EHOs) also known as Public Health Inspectors (PHIs) to inspect these food-service establishments and educate their operators to help prevent food-borne illnesses (FBIs). Data from inspections, comparing the types of establishment in terms of their food safety is limited. EHO continuously face challenges when trying to improve our food safety practices. Ensuring food safety in areas with ethnic diversity is one of their challenges. Diverse cultures have an array of type of restaurants, which make it more difficult for EHOs to be able to communicate and educate. Vancouver and the Fraser Valley area have a diverse culture with many different restaurant options. American research suggests that independently owned ethnic restaurants have a lower compliance rate with regulations and a higher risk of causing food-borne illnesses (Roberts et al., 2011). There is also evidence that the type of ownership of a restaurant (independently owned or chain) affects the compliance rate with health inspectors, with chains having better compliance. The 
British Columbia Centre for Disease Control (BCCDC) was interested in assessing whether a food safety margin exists between ethnic and non-ethnic restaurants and type of ownership in BC. This research project investigated $\mathrm{EHO}$ inspection reports, assessing whether a compliance rate difference exists between restaurant types, and assessed areas of food safety training to focus on.

\section{LITERATURE REVIEW}

\section{Food-borne Illness}

The Public Health Agency of Canada’s (PHAC) definition of FBI is "A human illness, with evidence indicating a food was the source of exposure to the contaminant causing illness. Foodborne illness occurs when a person consumes food contaminated with bacteria, viruses, parasites, or toxins” PHAC, 2010. An estimated 4 million Canadians (one in eight people) become ill every year from a food-borne illness (Thomas et al., 2013). In British Columba, over 900,000 people acquire a food-borne illness each year (BCCDC, 2013). Improving food safety in the home is important but this review will focus on full-serve restaurants. Large portions of Canadian meals are consumed in restaurants. In 2007, \$142 billion was spent on food, while $\$ 50$ billion of that was spent in restaurants and bars (Statistics Canada, 2012). Canada is known to be a leader in food safety. That being said, the economic, and social burdens of food-borne illnesses are severe and the room for improvement is sizeable (PHAC, 2013). The leading pathogens, which account for $90 \%$ of all foodborne illnesses in Canada are Norovirus, Clostridium perfringens, campylobacter spp, and Salmonella. Public Health Inspectors in Ontario rated their top four pathogens of concern, Salmonella, Campylobacter, E.coli, and Listeria monocytogenes (Thomas et al., 2013).

\section{Fraser Health}

In Fraser Health (along with the other health authorities in BC) restaurant inspections are routinely performed. EHOs conduct the inspections and enforce the BC Public Health Act and Food Premise Regulations. The EHOs have a geographic boundary in which they inspect all the restaurants in their area. Routine inspections are usually carried out once per year unless the risk of the establishment is high (FHA, 2011). Each Health Authority in BC has their inspection reports available online, for the public to view. Fraser Health's inspection reports consist of five main categories of violations: i) Construction and Approvals, ii) Control of Food Hazards, iii) Maintenance and Sanitation, iv) Hygiene and Communicable Diseases, and v) Education and
Training. The violations are coded with a number and correspond to a certain section in the B.C. Food Premise Regulation (under the B.C. Public Health Act). Each Food Service Establishment must follow these regulations. The online inspection reports show the number of violations observed (critical or noncritical) during the inspection and the description (FHA, 2014). An overall hazard rating of low, moderate or high is also on the report.

\section{Restaurant Risk Factors}

The Environmental Health Services (EHS) branch of the U.S. Centre for Disease Control and Prevention (CDC) states that more than half of foodborne illnesses are associated with restaurants, or other food service establishments (CDC, 2013). A 2011 research report found restaurant operations in the U.S. have been reported to be implicated in 52\% $59 \%$ of food-borne illness outbreaks (Roberts, Kwon, Shanklin, Liu, \& Yen, 2011). They revealed that risk factors for restaurants fall into the following three categories: i) Employee and manager food safety training, ii) Restaurant and food worker business, and iii) Type of ownership (chain vs non-chain) (Brown, 2013). According to their studies, restaurants in which employees and managers have food safety training are less likely to be implicated with a foodborne illness. In a 2003 study, only 32\% of restaurants associated with an outbreak had a certified kitchen manager trained in food safety, where as, $71 \%$ of non-outbreak restaurants had a trained manager (Hedberg et al., 2006). Restaurants that are busy have employees more likely to refrain from washing their hands and to still attend work when ill (Brown, 2013). Chain restaurant employees are more likely to use thermometers and wear gloves. In addition, chains are more likely to serve pasteurized shell eggs than independently owned restaurants (Green et al., 2007). These findings indicate chain restaurants and restaurants in which food safety training is required have a lesser chance of causing a food-borne illness.

Research has shown that most restaurant outbreaks can be accredited to improper employee preparation practices. To improve on these food safety practices, operator and employee intervention is needed but a lasting behavior change will not take place without education. Important food preparation practices include hand washing, cross-contamination prevention, glove use, holding (food above $60{ }^{\circ} \mathrm{C}$, or below $4{ }^{\circ} \mathrm{C}$ ), proper cooling, and proper reheating (Green \& Selman, 2005). A survey of Ontario Public Health Inspectors found out what inspectors thought was the most important risk factors. Their top six in decreasing order of importance were time- 
temperature abuse, cross contamination, inadequate hand washing, personal hygiene of food handlers, poor house keeping and inadequate sanitation (Pham \& Jones, 2012).

\section{Comparing Restaurants using Food Safety Risk Factors}

Comparing food safety practices from one restaurant to another can be difficult. There are many different risk factors to consider. Methods previously performed include; surveying of operators to learn the effectiveness of their food safety procedures, identifying which restaurants have recently been linked to food-borne illnesses, or comparing public health inspection reports. The problem with surveys is bias an operator may have towards his or her own establishment. Analyzing food-borne illness cases would not be a fair representation of which restaurants cause FBIs because many cases get under reported (PHAC, 2013). Comparing health inspection reports is useful because studies indicate that an increase in the number of violations increases the risk of causing a FBI. Important violations to assess the risk of an establishment are: i) food not from a safe source, ii) improper holding time/temperature, iii) inadequate cooking, and iv) contaminated equipment (Sharkey, Alam, Mase, \& Ying, 2012). Three risk factors to consider analyzing are: i) The number of violations, ii) number of critical violations, and iii) number of follow up to routine inspections.

A Kansas study by Roberts et al., 2011, used inspection violation data for ethnic and non-ethnic restaurants to assess compliance against their food code. Critical and non-critical violations were compared. Different ownership (independent or chain) type was used as another factor in the study. Almost 500 inspection reports were analyzed and split into four categories: Ethnic-independent, ethnicchain, non-ethnic-independent and non-ethnic chain. Independent ethnic restaurants had significantly more violations than the three other categories $(p=0.001)$ (Roberts et al., 2011). A study with a similar purpose in Florida used actual food-borne illness data to determine the food safety trends in Ethnic Restaurants. It defined ethnic restaurants as being Mexican, Italian or Asian (as these are the most popular ethnic restaurants in the region) (Simonne \& Nille, 2004). The sample size in this report was smaller than that of Roberts, et al.. 2011, however, it was able to identify more of a causative relationship between food handling practices and specific diseases. The findings in both studies stressed the importance of food safety professionals learning about issues and risk related to ethnic foods. The study done by Roberts et al, is very similar to the one proposed for this project. The data from the U.S. may be similar to food safety trends in Fraser Health or the rest of Canada. However, doing the research in Fraser Health is still important because the ethnic culture is different, and to the best of the author's knowledge, there is no literature on the specific topic.

\section{Ethnic Restaurants}

In the United States, the percentage of total FBI outbreaks among ethnic restaurants increased from $3 \%$ to $10 \%$ from 1990 to 2000 (Simonne \& Nille, 2004). A study completed in 2006 in the U.S., discussed why ethnic food establishments are of concern (Mauer et al., 2006). Food safety professionals and inspectors were surveyed to help identify which ethnic foods professionals lacked food safety knowledge, and to describe their general food safety concerns with ethnic establishments. The food types that food professionals were not knowledgeable about were vast. A survey of Chinese restaurant operators expressed that understanding the health inspector was a challenge (Liu \& Kwon, 2013). It is clear that addressing this communication barrier is necessary to help inspectors and operators. Their most common restaurants encountered in the 2006 U.S. study were Chinese, Mexican and South Asian. The top three food products which professionals did not have confident food safety knowledge of were sushi/sashimi, peking duck and balut (duck embryo). Lack of knowledge and lack of ethnic food safety guidelines will affect inspector's ability to educate and consequently affect the ability to prevent food borne illness (Mauer et al., 2006). Furthermore, this study found out what professionals believed were the high-risk practices in ethnic restaurants. In retail establishments the concerns were food being obtained from unapproved sources. For restaurants; lack of knowledge and understanding of food safety, temperature abuse, cross-contamination, and improper hygiene were highlighted in the survey from professionals. Inspectors also noted language barriers were a significant challenge in conveying food safety knowledge. The infractions identified in this survey are common, general infractions, and it does not give comparative data to non-ethnic restaurants.

According to yelp.ca, Chinese restaurants are the most prevalent ethnic restaurants in Fraser Health. Exploring if and where EHOs need to improve Chinese food safety is very important. Some of the barriers to improving food safety in Chinese restaurants are lack of money to send employees for training, lack of time, lack of perceived need for training, and other cultural differences (Liu \& Kwon, 2013). One of the main cultural differences between 
Chinese and non-Chinese restaurants operators that health inspectors should be aware of is the values of respect and saving face. If health inspectors show respect and do not put operators in a position where they will lose face to their customers, employees, family or inspector then food safety education and compliance may be easier (Liu \& Kwon, 2013).

\section{Restaurant Inspections}

Restaurant inspections are widely used as a method to educate operators, and enforce regulations to prevent food-borne illnesses. Whether in the U.S. or Canada, many local health areas make their inspection report public. Jones et al, 2004 claims an effective inspection system should be uniform, consistent, and focused on identifying characteristics known to affect food safety. There are researchers who disagree in the need for uniform, consistent inspections. Roberts et al., 2011 expresses that separate training and intervention programs are needed in ethnic restaurants. It is important for inspectors to put different weights to different violations. Items or actions that do not cause an immediate health hazard are lower risk. These factors can include conditions of surfaces that do not contact food, floors, walls, ceilings, lighting and ventilation. Critical items like employee hygiene or storage of potentially hazardous foods are more valid assessment of the risk of an establishment (Jones, Pavlin, LaFleur, Ingram, \& Schaffner, 2004). Acknowledging the difference between critical and non-critical violations is imperative for comparing restaurant inspection reports in this project. A 2012 U.S. study indicated that restaurants with increased critical violations do not cause more diseases than those with less (Yeager et a., 2012). The report examined two groups of restaurants; ones with high number of critical violations and ones with low, and tested the bacterial load of pathogens with random food samples. No statistical difference occurred in the pathogen content between the two restaurant groups. However the report did highlight, that several foods contained Staphylococcus aureus in both groups (Yeager et al., 2012). S.aureus is a toxinproducing pathogen indicating poor employee hygiene and temperature abuse.

Inspection frequency can change depending on the health authority involved and the risk level of the establishments. A high-risk establishment will have more frequent routine inspections. In Ontario, a study was done where inspection frequency of restaurants was increased. Restaurants were assigned three, four or five inspections per year. The change in the frequency of inspections did not result in a significant difference between critical or non-critical infractions (Newbold, McKeary, Hart, \& Hall, 2008).

Posting inspection reports online is intended to inform the public and to encourage operators to comply with the health inspector and the food premise regulation. 2,995 Utah restaurants were studied before and after the implementation of posting inspection reports. Critical violations did decrease significantly (Waters et al., 2013). Fraser Health posts their inspection reports online for public access. Clearly restaurants care about public opinion, therefore campaigning to the public that inspection reports are readily available may be a recommendation that will improve general food safety.

\section{METHODS}

The author, using Fraser Health's online database gathered data from 270 different health inspection reports completed between January 2012 and January 2014, located in Burnaby, Surrey and New Westminster A total of 90 independently owned ethnic, 30 independently owned, non-ethnic and 30 non-ethnic chain restaurants were analyzed. The inspection reports were taken from HealthSpace, which is Fraser Health's software program for storing their reports. EHOs conduct inspections, write up their inspection reports and then they enter Health Space where the public is free to access a summary of the findings for all food-establishments. The number of critical, and non-critical violations from online inspection reports was compared using three categories for restaurant types as seen in table 1:

Table 1: Consists of a description of each type of restaurant category used by the author.

\section{Category Description}

A) Independent Full-serve, independently Ethnic (IE) owned Japanese, Chinese, and Indian restaurants (30 samples of each).

B) Independent

Non-ethnic (INE)

Full-serve, independently owned restaurants which do not claim to predominantly serve food from a culture outside of Canada and U.S.A.

C) Chain NonEthnic (CNE)
Full-serve, non-independently owned restaurants which do not claim to predominantly serve food from a culture outside of Canada and U.S.A. 
The author used Yelp.ca (C) search parameters to obtain all available restaurants in each category in the applicable geographic areas. Yelp is a website that can be used to search for certain restaurants, or other local businesses (Yelp, 2013). For each category, all restaurants selected were restricted to be located in municipalities of Burnaby, New Westminster, and Surrey. Once a list of restaurants was generated in each category, the author used Microsoft Excel to generate a random order, too ensure no bias was used in selecting which restaurants to sample. If a restaurant could not be used another was randomly selected in its place.

When EHOs conduct an inspection they use a paper or digital copy of the "Food Premises Inspection Report” form. The form lists all the violations that a restaurant could commit. Each violation refers to the section of the B.C. Food Premise Regulation (under the BC Public Health Act) that the violation is breaking (B.C. Laws, 2013). There are 13 critical violations and 25 different noncritical violations. More critical and non-critical violations will result in a higher risk of causing a food-borne illness. Both violations contribute to the overall inspection score. Critical violations are weighted higher and contribute more significantly to the overall score. This is because they are infractions that are the most severe and will cause a greater risk to the public than having a non-critical violation. Depending on the overall inspection score, an establishment will be labeled as having a Low, Moderate or High Hazard Rating (Fraser Health, 2013). A copy of the "Food Premises Inspection Report” is shown below in Figure 1. The author gathered the following data from each inspection report: i) Date of inspection, ii) Number of critical violations, iii) Number of non-critical violations, iv) Hazard Rating (Low, Moderate or High), v) Each violation code listed. 
Figure 1: Fraser Health Food Premises Inspection Report

fraserhealth

FOOD PREMISES INSPECTION REPORT Health Protection

Rpt \#:

FOOD PREMISES HAZARD RATING CHECKLIST

\begin{tabular}{|c|c|c|c|c|c|}
\hline \multirow[t]{2}{*}{ CODE } & \multicolumn{2}{|l|}{ VIOLATION CATEGORY } & \multicolumn{3}{|c|}{$\begin{array}{l}\text { VIOLATION } \\
\text { SCORE }\end{array}$} \\
\hline & \multicolumn{2}{|l|}{ Construction and Approvals } & L & $\mathbf{M}$ & $\mathrm{H}$ \\
\hline 101 & \multicolumn{2}{|l|}{ Plans/construction/alterations not in accordance with the Regulation [s. 3; s. 4] } & 1 & 3 & 5 \\
\hline 102 & \multicolumn{2}{|l|}{ Operation of an unapproved food premises [s. $6(1)]$} & 1 & 3 & 5 \\
\hline 103 & \multicolumn{2}{|l|}{ Failure to hold a valid permit while operating a food service establishment [s. 8(1)] } & 1 & & \\
\hline \multirow[t]{2}{*}{104} & \multicolumn{2}{|l|}{ Permit not posted in a conspicuous location [s. 8(7)] } & 1 & & \\
\hline & \multicolumn{2}{|l|}{ Control of Food Hazards } & & & \\
\hline $201^{*}$ & \multicolumn{2}{|l|}{ Food contaminated or unfit for human consumption [s 13] } & 5 & 15 & 25 \\
\hline $202^{*}$ & \multicolumn{2}{|l|}{ Food not processed in a manner that makes it safe to eat [s. 14(1)] } & 5 & 15 & 25 \\
\hline $203^{\star}$ & \multicolumn{2}{|l|}{ Food not cooled in an acceptable manner [s. 12(a)] } & 5 & 15 & 25 \\
\hline $204^{*}$ & \multicolumn{2}{|l|}{ Food not cooked or reheated in a manner that makes it safe to eat [s 14(1)] } & 5 & 15 & 25 \\
\hline $205^{*}$ & \multicolumn{2}{|l|}{ Cold potentially hazardous food stored/displayed above $4^{\circ} \mathrm{C} .[\mathrm{s} .14(2)]$} & 5 & 15 & 25 \\
\hline $206 *$ & \multicolumn{2}{|l|}{ Hot potentially hazardous food stored/displayed below $60^{\circ} \mathrm{C}$ [s $\left.14(2)\right]$} & 5 & 15 & 25 \\
\hline $207^{\star}$ & \multicolumn{2}{|l|}{ Previously served food not discarded [s. 15] } & 5 & 15 & 25 \\
\hline 208 & \multicolumn{2}{|l|}{ Foods obtained from unapproved sources [s. 11] } & 3 & 9 & 15 \\
\hline 209 & \multicolumn{2}{|l|}{ Food not protected from contamination [s. 12(a)] } & 3 & 9 & 15 \\
\hline 210 & \multicolumn{2}{|l|}{ Food not thawed in an acceptable manner [s. 14(2)] } & 1 & 3 & 5 \\
\hline 211 & \multicolumn{2}{|l|}{ Frozen potentially hazardous food stored/displayed above $-18^{\circ} \mathrm{C}$. [s. $\left.14(3)\right]$} & 1 & & \\
\hline \multirow[t]{2}{*}{212} & \multicolumn{2}{|l|}{ Operator has not provided acceptable written food handling procedures [s. 23] } & 1 & 3 & \\
\hline & Maintenance and Sanitation & & & & \\
\hline $301^{\star}$ & Equipment/utensils/food contact surfaces not maintained in sanitary cond & s. $17 ; s .16(c)]$ & 5 & 15 & 25 \\
\hline $302^{*}$ & Equipment/utensils/food contact surfaces not properly washed and sanitiz & $17(2)]$ & 5 & 15 & 25 \\
\hline $303^{*}$ & Equipment/facilities/hot \& cold water for sanitary maintenance not adequa & $17(3) ;$ s. $4(1)(f)]$ & 5 & 15 & 25 \\
\hline 304 & Premises not free of pests [s. 26(a)] & & 3 & 9 & 15 \\
\hline 305 & Conditions observed that may allow entrance/harbouring/breeding of pest & $6(b),(c)]$ & 3 & 9 & 15 \\
\hline 306 & Food premises not maintained in a sanitary condition [s. 17(1)] & & 3 & 9 & 15 \\
\hline 307 & Equipment/utensils/food contact surfaces not of suitable design/material [ & s. 19] & 3 & 9 & 15 \\
\hline 308 & Equipment/utensils/food contact surfaces not in good working order [s. 16 & 19J & 3 & 9 & 15 \\
\hline 309 & Chemicals, cleansers, \& similar agents stored or labeled improperly [s. 27 & & 3 & 9 & 15 \\
\hline 310 & Single use containers \& utensils are used more than once [s. 20] & & 3 & 9 & 15 \\
\hline 311 & Premises not maintained as per approved plans $[s .6(1)(b)]$ & & 1 & 3 & 5 \\
\hline 312 & Items not required for food premises operation being stored on the premis & $18 \mathrm{~J}$ & 1 & 3 & 5 \\
\hline 313 & Live animal on the premises, excluding guide animal in approved areas [s & & 1 & 3 & 5 \\
\hline 314 & Operator has not provided acceptable written sanitation procedures [s. 24 & & 1 & 3 & \\
\hline 315 & Refrigeration units and hot holding equipment lack accurate thermometer & $9(2)]$ & 1 & & \\
\hline & Hygiene and Communicable Diseases & & & & \\
\hline $401^{*}$ & Adequate handwashing stations not available for employees [s. 21(4)] & & 5 & 15 & 25 \\
\hline $402^{*}$ & Employee does not wash hands properly or at adequate frequency is 21 & & 5 & 15 & 25 \\
\hline 403 & Employee lacks good personal hygiene, clean clothing and hair control [s & & 3 & 9 & 15 \\
\hline 404 & Employee smoking in food preparation/processing/storage areas [s. 21(2) & & 3 & 9 & \\
\hline $405^{*}$ & III staff not excluded from contact with food or food equipment/utensils [s. & & & & 25 \\
\hline & Education and Training & & & & \\
\hline 501 & Operator does not have FOODSAFE Level 1 or Equivalent [s. 10(1)] & & 1 & & \\
\hline 502 & In operator's absence, no staff on duty has FOODSAFE Level 1 or equiva & s. $10(2)]$ & 1 & & \\
\hline & HAZARD RATING SCALE & SUBTOTAL $=$ & & & \\
\hline LOW: & MODERATE: $16-29$ & TOTAL $=$ & & & \\
\hline
\end{tabular}




\section{Reliability and Validity}

To ensure valid results the author modeled the study off of another peer-reviewed experiment. A sample size of 90 in the independent ethnic restaurant category was obtained, but 30 in the others. A size of at least 30 each of three categories allows there to be sufficiently large data to obtain statistically valid and reliable results. Using 90 ethnic restaurants (30 of each Japanese, Chinese and Indian) allowed the author to compare the individual ethnic restaurants as well. The data collection was very simple and a consistent method was applied for each sample. This consistency adds to the validity of the design.

There are challenges in the study that can lead to lack of reliability. The author used many different inspection reports without knowing how many different inspectors filled out the forms. Each inspector will have a different style and may fill out the number of violations differently than another inspector. To reduce this risk the author only used inspection reports within a two-year period.

Management and polices change over time, so having this timeline restriction reduces variability in inspectors styles. Additionally, all the inspectors are from the same health authority because all the restaurants being samples are within Fraser Health.

\section{Ethical Considerations}

This study consisted of analyzing data that is available to the public. Online Inspection reports are available to anyone who wishes to view them online. Using public data to create a study has little ethical concern. That being said, the author must be careful not to portray any bias. Bias in the report may unfairly bring a negative implication to a restaurant or a member of the public. The author avoided this by not sharing the names of the individual restaurants analyzed. The names of the restaurants are also not important to the validity of the study.

\section{Pilot Study}

The pilot study consisted of executing the exact experimental design written in this report but with only 10 samples in each restaurant category. The statistical analysis is not valid with only 10 restaurants; however, the purpose was to allow the author to obtain an idea of the feasibility, and efficiency of the proposed experimental design. The raw data was recorded in the table shown in Appendix E and F. This pilot study was successful and the method of collecting samples from Yelp was successful.

\section{STATISTICAL ANALYSIS}

\section{Description of Data}

This study has nominal, numerical and ordinal data as described in table 2.

Table 2: Description of the type of data collection.

\section{Data}

Dates of Inspection

Number of critical violations

$\begin{array}{ll}\begin{array}{l}\text { Number of non-critical } \\ \text { violations }\end{array} & \text { Numerical } \\ \begin{array}{l}\text { Hazard Rating (Low, } \\ \text { Medium or High) }\end{array} & \text { Ordinal } \\ \begin{array}{l}\text { Each violation code } \\ \text { listed }\end{array} & \text { Numerical }\end{array}$

\section{Descriptive Statistics}

The data used for descriptive statistics are the number of critical and non-critical violations, the hazard ratings, and the individual violation codes. Microsoft Excel was used for all the descriptive statistics. A summary of statistics (mean, median mode, standard error, standard deviation, variance, range, minimum, maximum, sum and count) was used to compare the restaurant types, shown in table 3. Hazard ratings and violation code frequencies are displayed in graphical form (Figures 1 and 2).

\section{Inferential Statistics}

A one-way ANOVA inferential statistical test was used to comparing critical violations between the 3 restaurant categories. Microsoft Excel was used for the raw data and NCSS is used for the inferential statistical analysis (NCSS, 2007). A full NCSS data output is attached to this report (in Appendix G). The raw data entry sheet template is in Appendix E, and the raw data used for the descriptive and inferential statistics are in Appendix F.

\section{Hypothesis (null and alternate)}

Ho $=$ The mean number of critical violations are not significantly different between Independent Ethnic (IE), Independent Non-ethnic (INE), and Chain NonEthnic (CNE) restaurants. 
Ha $=$ The mean number of critical violations are significantly different between Independent Ethnic (IE), Independent Non-ethnic (INE), and Chain NonEthnic (CNE) restaurants.

\section{SECTION 6: RESULTS}

\subsection{Descriptive Test Results}

Table 3i: Descriptive statistics for the number of critical violations between each restaurant type.

\begin{tabular}{|l|c|c|c|c|c|c|}
\hline & \multicolumn{2}{|l|}{$\begin{array}{l}\text { Chain Non- } \\
\text { Ethnic }\end{array}$} & \multicolumn{2}{l|}{$\begin{array}{l}\text { Independent- } \\
\text { Non-Ethnic }\end{array}$} & \multicolumn{2}{l|}{$\begin{array}{l}\text { Ethnic } \\
\text { (Independent }\end{array}$} \\
\hline & $\begin{array}{l}\text { Crit } \\
\text { ical }\end{array}$ & $\begin{array}{l}\text { Non- } \\
\text { Critica } \\
\text { l }\end{array}$ & $\begin{array}{l}\text { Crit } \\
\text { ical }\end{array}$ & $\begin{array}{l}\text { Non- } \\
\text { Critica } \\
\text { l }\end{array}$ & $\begin{array}{l}\text { Crit } \\
\text { ical }\end{array}$ & $\begin{array}{l}\text { Non- } \\
\text { Critica } \\
\text { l }\end{array}$ \\
\hline $\begin{array}{l}\text { Mea } \\
\text { n }\end{array}$ & 0.93 & 1.5 & 1.2 & 1.9 & 1.6 & 2.5 \\
\hline $\begin{array}{l}\text { Med } \\
\text { ian }\end{array}$ & 1 & 1 & 1 & 1.5 & 1 & 2 \\
\hline $\begin{array}{l}\text { Mod } \\
\text { e }\end{array}$ & 0 & 0 & 0 & 1 & 0 & 2 \\
\hline SD & 0.98 & 1.33 & 1.1 & 1.5 & 1.46 & 2 \\
\hline $\begin{array}{l}\text { Cou } \\
\text { nt }\end{array}$ & 30 & 30 & 30 & 30 & 90 & 90 \\
\hline
\end{tabular}

Table 3ii: Number of Critical Violations for each ethnic restaurant type.

\begin{tabular}{|l|l|c|c|}
\hline & $\begin{array}{l}\text { Indian } \\
\text { Restaurants }\end{array}$ & $\begin{array}{l}\text { Chinese } \\
\text { Restaurants }\end{array}$ & $\begin{array}{l}\text { Japanese } \\
\text { Restaurants }\end{array}$ \\
\hline Mean & 1.1 & 1.6 & 1.9 \\
\hline SD & 1.1 & 1.1 & 1.1 \\
\hline Count & 30 & 30 & 30 \\
\hline
\end{tabular}

The mean number of critical and non-critical violations of ethnic restaurants are the highest, followed by Independent non-ethnic restaurants. A one -way ANOVA was conducted to see if there is a statistical significant difference in the means (see inferential results).

Restaurants, at the end of each inspection attain an overall hazard rating of Low, Moderate of High. The hazard rating results from all the restaurants sampled are shown below in Figure 2. 


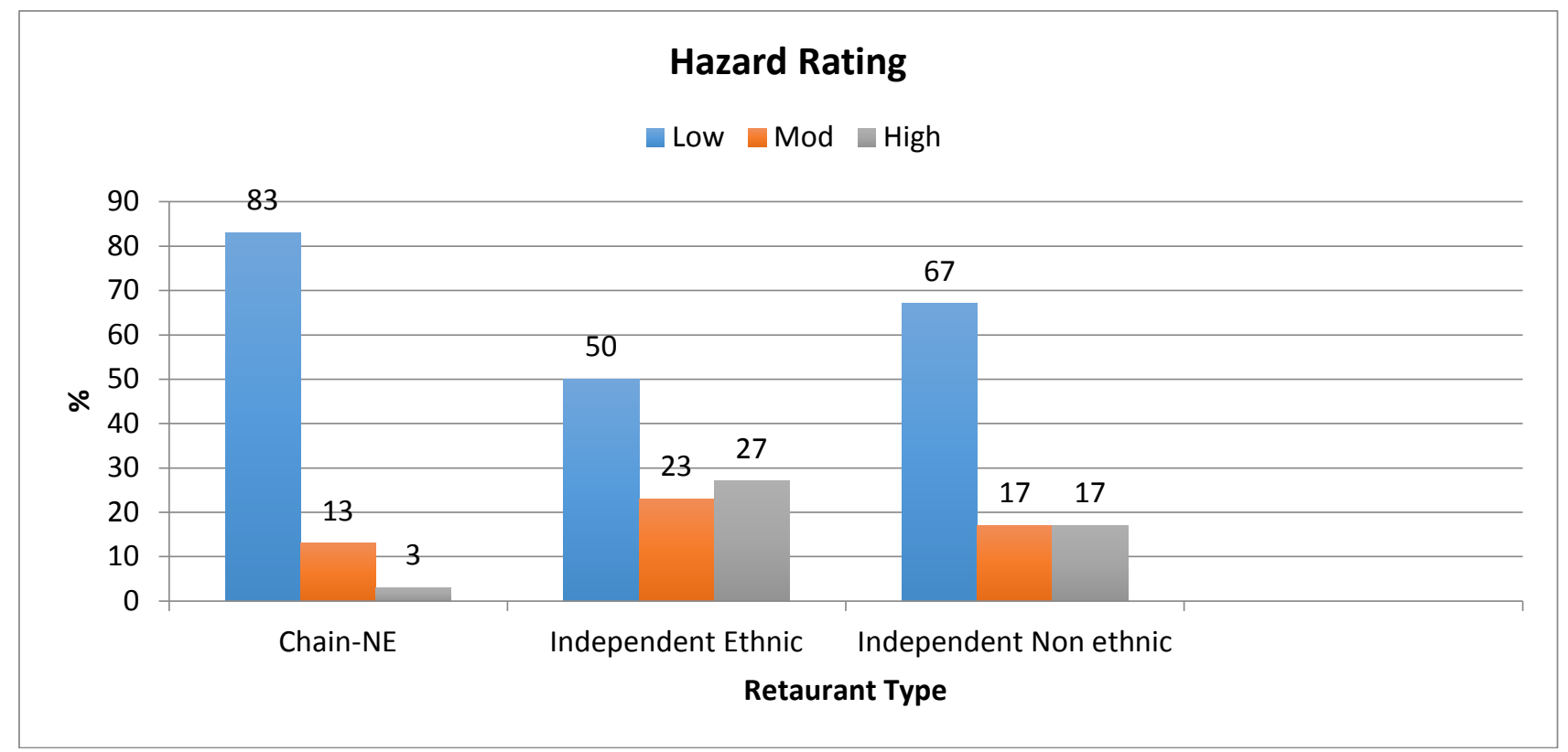

Figure 2: Percentage of each hazard rating (low, moderate and high) for each restaurant type sampled.

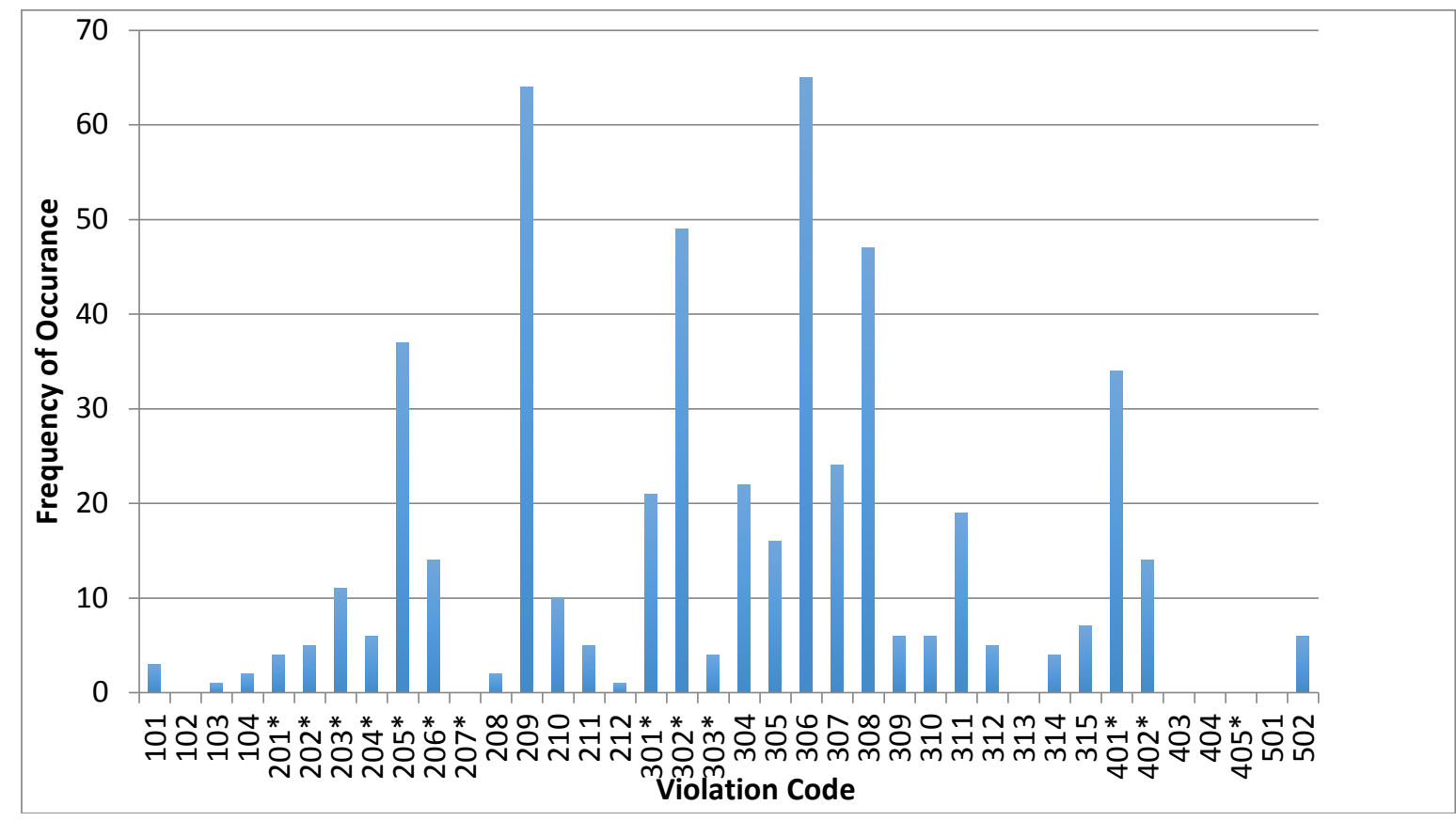

Figure 3: Total number of all types of Violations for all 150 restaurants involved in the study. A full list stating what each violation code is can be found in Appendix C.

Codes with a “*”Refers to the Critical Violations.

101-104 Construction and Approvals Violations

201-212 Control of Food Hazards Violations

301-315 Maintenance and Sanitation Violations

401-405 Hygiene and Communicable Diseases Violations

501-502 Education and Training Violations

\section{Inferential Test Results}

A total of four one-way ANOVA's and one Chi squared test were used to analyze the results. The 
table 4 describes the tests results and the hypotheses are below. Each ANOVA test failed the test of assumptions meaning the data was non-parametric (not normally distributed). Therefore, the Kruskal Wallis (aka non-parametric ANOVA) test was used.

Table 4: Inferential statistics summary.

\begin{tabular}{|c|c|c|c|}
\hline Test & Comparing & $\begin{array}{l}\text { P-Value } \\
\text { (Corrected } \\
\text { for Ties) }\end{array}$ & $\begin{array}{l}\text { Result } \\
\text { (alpha=0.0 } \\
\text { 5) }\end{array}$ \\
\hline $\begin{array}{l}\text { i) } \\
\text { ANOVA/ } \\
\text { Kruskal } \\
\text { Wallis }\end{array}$ & $\begin{array}{l}\text { Critical } \\
\text { Violations }\end{array}$ & 0.09 & $\begin{array}{l}\text { Can not } \\
\text { reject Ho }\end{array}$ \\
\hline $\begin{array}{l}\text { ii) } \\
\text { ANOVA/ } \\
\text { KW }\end{array}$ & $\begin{array}{l}\text { Non-Critical } \\
\text { Violations }\end{array}$ & 0.033 & $\begin{array}{l}\text { Reject Ho, } \\
\text { Accept Ha }\end{array}$ \\
\hline $\begin{array}{l}\text { iii) } \\
\text { ANOVA/ } \\
\text { KW }\end{array}$ & $\begin{array}{l}\text { Critical } \\
\text { Violations } \\
\text { (Comparing } \\
\text { Ethnic } \\
\text { restaurants: } \\
\text { separately) }\end{array}$ & 0.044 & $\begin{array}{l}\text { Reject Ho, } \\
\text { Accept Ha }\end{array}$ \\
\hline $\begin{array}{l}\text { iv) Chi } \\
\text { Squared }\end{array}$ & Hazard Rating & 0.017 & $\begin{array}{l}\text { Reject Ho, } \\
\text { Accept Ha }\end{array}$ \\
\hline $\begin{array}{l}\text { v) } \\
\text { ANOVA/ } \\
\text { KW }\end{array}$ & $\begin{array}{l}\text { Critical } \\
\text { Violations } \\
\text { (Indian } \\
\text { restaurants } \\
\text { removed) }\end{array}$ & 0.037 & $\begin{array}{l}\text { Reject Ho, } \\
\text { Accept Ha }\end{array}$ \\
\hline
\end{tabular}

\section{Null and Alternate Hypothesis's:}

i) $\mathbf{H o}=$ The mean number of critical violations are not significantly different between the three restaurant types.

$\mathbf{H a}=$ The mean number of critical violations are significantly different between the three restaurant types ii) $\mathbf{H o}=$ The mean number of non-critical violations are not significantly different between the three restaurant types.

$\mathbf{H a}=$ The mean number of critical violations are significantly different between the three restaurant types

iii) $\mathbf{H o}=$ The mean number of critical violations are not significantly different between all restaurant categories (Indian, Japanese, Chinese, Chain Nonethnic, and Independent Non-Ethnic).

$\mathbf{H a}=$ The mean number of critical violations are significantly different between all restaurant categories (Indian, Japanese, Chinese, Chain Nonethnic, and Independent Non-Ethnic).

iv) $\mathbf{H o}=$ Inspection hazard rating (Low, Mod, High) and restaurant type (Independent Ethnic, Chain Nonethnic, and Independent Non-Ethnic) and independent.

$\mathbf{H a}=$ Inspection hazard rating and restaurant category are not independent.

V) $\mathbf{H o}=$ The mean number of critical violations are not significantly different between the restaurant categories: Japanese, Chinese, Chain Non-ethnic, and Independent Non-Ethnic.

$\mathbf{H a}=$ The mean number of critical violations are significantly different between the restaurant categories: Japanese, Chinese, Chain Non-ethnic, and Independent Non-Ethnic.

Results of the Tukey-Kramer multiple comparison test was reviewed for the second and fifth test. In test ii), the Ho was rejected and the alternative, the number of non-critical violations between restaurant types is significantly different, was accepted. The Tukey-Kramer test showed that the only restaurant type that was different was independent ethnic restaurants with a mean number of non-critical violations at 2.5. In test iii), despite having a p-value of 0.044 , the multiple comparison tests did not show any restaurant category significantly different from each other. An additional test was done to see the effects of removing Indian restaurants from ANOVA tests. The results showed the restaurant types were more significantly different $(p=0.037)$ than the similar previous test $(p=0.044)$. A Tukey-Kramer test indicated that the only restaurant category, which was significantly different, was Japanese restaurants (mean critical violation $=1.9$ ) from Chain, non-ethnic restaurants (mean critical violations $=0.93)$. 
Table 5: Chi Squared contingency table. Hazard rating (low, mod, high) is the independent variable and restaurant type is the dependent.

\begin{tabular}{|l|r|r|r|}
\hline & \multicolumn{1}{|l|}{ Low } & Mod & High \\
\hline Chain-NE & 25 & 4 & 1 \\
\hline Ethnic & 45 & 21 & 24 \\
\hline $\begin{array}{l}\text { Independent- Non } \\
\text { ethnic }\end{array}$ & 20 & 5 & 5 \\
\hline
\end{tabular}

A P-value of 0.017 indicates there is an association between restaurant type and rating.

\section{Type (alpha) 1 and Type 2 (beta) errors}

Type 1: There is no difference even though the test says there is. A Type 1 error may exist in tests ii) $\mathrm{p}=0.033$, iii) $\mathrm{p}=0.044$, and $\mathrm{V}$ ) $\mathrm{p}=0.037$. These $\mathrm{p}=$ values were close to the alpha set at 0.05 . You can help control alpha by lowering/changing the alpha. Test iii) has a p-value of 0.017 . The risk of an alpha error is lower in this test but it still exists. Lowering the alpha significance to a more strict level of 0.01 instead of 0.05 would drastically change the results. The other ANOVA (test i)) had a p-value ( $\mathrm{p}=0.090$ higher than the alpha, indicating a significant difference did not exist. The test was comparing the number of critical violations between restaurant types. In this situation the possibility for a type two, beta error, was high. A type two error exists when the tests says there is no difference and when the truth says there is. The power for this test (test i)) was $58 \%$. The confidence in a test is stronger when the power is above $80 \%$. To lower the chance of beta error and increase the power, a larger sample size could be chosen (Heacock \& Sidhu, 2013).

\section{DISCUSSION}

Ultimately, the purpose of this study was to find out if the level of food safety is associated with the type of ownership (chain vs independent) or ethnicity of a restaurant. The author used various descriptive and inferential statistics to explore the data.

\section{Violations and Risk}

Table 3 is a summary of statistics for the number of critical and non-critical violations observed. This table shows independently owned ethnic restaurants to have the highest mean number critical violations and non-critical violations followed by independent non-ethnic, and then the least number of violations being with chain non-ethic restaurants. To test whether these differences are significant, a one-way ANOVA was used. The first test was comparing the number of critical violations between restaurant types. The result showed a p-value of 0.09 . At alpha of 0.05 this means the null hypothesis cannot be rejected $(\mathrm{P}>0.05)$. The number of critical violations between restaurant groups cannot be considered as significantly different even though one may think differently by viewing the descriptive statistics.

Since the Ho could not be rejected, the author analyzed the ethnic restaurants separately (Japanese, Chinese, Indian) with another one-way non-parametric ANOVA (Kruskal Wallis). The results of this analysis indicated a statistically significant difference in the number of critical violations $(p=0.044)$. Further analysis of the data showed that Japanese restaurants had the highest number of critical violations but was only significantly greater than chain, non-ethnic restaurants.

The number of non-critical violations was significantly different between each restaurant category. The null hypothesis in this instance was rejected because the $p$-value was $0.033(p<0.05)$. If the alpha was set more strictly, at 0.01 , the Ho could not be rejected. This shows why, in this case, there was a high chance of a type 1 (alpha) error.

There was a significant difference in the number of critical violations when ethnic restaurants were treated independently, but not when they were grouped as one. To assess the risk of an establishment critical violations are more of a factor than non-critical violations (Sharkey, Alam, Mase, \& Ying, 2012). This means if only violations from inspection reports are used to assess the risk to public health, then it is best to use the number of critical violations. Therefore, if only using violation data, one can not assume there is a significant difference in risk to the publics health between the three restaurant types (Chain non-ethnic, independent non-ethnic, and independent ethnic), but there is a difference within the ethnicities. The one significant finding in the critical violation data is Japanese restaurants have a higher risk to the public compared to chain nonethnic restaurants.

The review of literature suggested that ethnic restaurants would have a higher number of critical violations (Roberts, et al. 2011). That report showed that ethnic restaurants had significantly more violations $(\mathrm{p}=0.001)$ compared to the other restaurant 
types. Reasons for this difference could include the different inspection styles in Fraser Health compare to in Kansas. Or the difference in type of predominant ethnic restaurants could explain the difference. Additionally, the food safety level in ethnic restaurant may be better in Fraser Health compared to Kansas. The results from the number of non-critical violations did agree with the literature and showed ethnic restaurants having more infractions.

Each specific violation was recorded during the analysis. Figure 3 shows two clear spikes with codes 209 and 306, which are both non-critical violations. Code 209 represents the violation "Food not protected from contamination”, and code 306 represents "Food premise not maintained in a sanitary condition. The top three critical violations committed by all restaurants were codes $302 *$ (33 \% of restaurants), 205* (25\% of restaurants and 401* (23 $\%$ of restaurants). The codes definitions are as follows:

- $\quad 302 *$ Equipment not properly washed and sanitized,

- $\quad 205 *$ - Cold potentially hazardous food stored above $4{ }^{\circ} \mathrm{C}$.

- $401 *$ - Adequate handwashing stations not available for employees

Japanese restaurants had the most frequent occurrence of each of the most common critical violations listed above. If EHOs can focus on lowering the number of these top three critical violations, it will have a great effect of lowering the overall total number of critical violations.

\section{Hazard Ratings}

After an EHO conducts an inspection of a restaurant, a final score is given and that relates to a hazard level. That hazard level, low, mod, or high is noted on the online inspection report. Figure 2 shows the how often each restaurant category had a low, mod, or high rating. The graph displays independent ethnic restaurants have the worst hazard rating. This is because they have the most 'high' ratings and the least 'low ratings. Dissimilar to the ANOVA, a Chi Squared test showed a significant association $(\mathrm{P}=0.017)$ between ethnic, chain non-ethnic, and independent non-ethnic. The chance for a type 1 error is possible. If alpha is lowered to 0.01, then the null hypothesis could not be rejected. The hazard rating results and number of violations do not agree with each other. One explanation for this could be that ethnic restaurants may not have more violations on average, but more severe.

\section{LIMITATIONS}

This study does have limitations that may negatively affect reliability and validity. The first limitation is regarding the EHO who fills out the inspection report. Each EHO could have different styles and levels of stringency. Also we do not know how severe each violation is by looking at the codes on the online inspection report. Research cited in the literature review suggested that the number of violations relates to the risk of an establishment, but the definition of a violation may differ from EHO to EHO. The next limitation is the generalizability of the study the entire population. Each health authority is different. Another similar study in a different health authority would help address this limitation. Using Yelp was also a limitation because it did not allow for a large sample size.

\section{RECCOMENDATIONS/ FUTURE RESEARCH}

Unlike the American reports cited in the literature review, there was not a drastic difference in number of violations. However if EHOs are looking to allocate their time more efficiently with inspections, this report suggest that ethnic restaurants have the most room for improvement, followed by independent non-ethnic, and then chain non-ethnic with the least need for improvement. If EHOs in BC want to lower the number of violations, focusing their education efforts on improving actions involving codes 209, 306 and 302* (Food not protected from contamination, Food premise not maintained in a sanitary condition, Equipment/utensils/food contact surfaces not maintained in sanitary condition) would have the greatest impact on lowering the total number of violations.

Having a section on the health inspection report for recording the ethnicity the restaurant is associated with (if any) would allow for the health authorities to do their own, automatic, statistical analysis. The analysis could compare number of violations, as done in this report, but with every restaurant samples, instead of only 150.

This report brought ideas for future studies. Doing a similar report in a different health authority would help the generalizability of the findings. A similar report could also compare another factor of restaurants with number of violations. These factors could include price (how expensive the restaurant is), age of restaurant, age of operator, number of staff, 
size of restaurant, date of inspection (data already collected in this report) and location. Additionally, a study investigating the food safety practices of Japanese restaurants could provide further answers for why they had the highest number of violations.

\section{CONCLUSION}

Overall the results were different than expected. The American studies referenced in the literature review suggested a drastic difference in risk to the public health between ethnic and non-ethnic restaurants, and chain and independently owned restaurants. In the area of Burnaby, New Westminster and Surrey, the type of ownership (independent vs chain) and the restaurant type were not a factor when looking at number of critical violations that a restaurant commits. Independent ethnic restaurants had the highest number mean number of critical violations. This was a result of Japanese restaurants, which had the highest number of infractions out of every category. These findings suggest a slight disparity in risk to public health between ethnic and non-ethnic restaurants.

\section{ACKNOWLEDGEMENTS}

Production of this report was made possible through the help of the author's supervisor, Helen Heacock, Instructor, Bobby Sidhu, and BCCDC contributors Lynn Wilcott and Lorrain McIntyre.

\section{REFERENCES}

BCCDC. (2013). Interview with Lorraine Mctintyre (Environmental Health Services) and Lynn Wilcott (Director of Food Protection Services). Information retrieved on October 3, 2013.

B.C. Laws. (2013). Food premise regulation B.C. Reg. 210/99. (C) Queens Printer. Victoria, B.C. Retrieved from http://www.bclaws.ca/EPLibraries/bclaws_n ew/document/ID/freeside/11_210_99

Brown, L. (2013). EHS-net restaurant food safety studies: what have we learned? Journal of Environmental Health, 75(7), 44-46. Retrieved from

http://origin.glb.cdc.gov/nceh/ehs/Docs/JEH/20 13/mar-ehsnet-food-safety-lgb.pdf

British Columbia Centre for Disease Control. 2013. Food \& your health. Retrieved from http://www.bccdc.ca/foodhealth/default.htm
Center for Disease Control and Prevention (CDC). (2013). Environmental Health Serivces: CDC offers new environmental health findings and tools to improve food safety in restaurants.

Retrieved from: http://www.cdc.gov/nceh/ehs/News/Features/2 013/JFP-articles.html

Green, L. R., Radke, V., Mason, R., Bushnell, L., Reimann, D. W., Mack, J. C., ... Selman, C. a. (2007). Factors related to food worker hand hygiene practices. Journal of Food Protection, 70(3), 661-6. Retrieved from http://www.ncbi.nlm.nih.gov/pubmed/1738805 6

Green, L. R., \& Selman, C. (2005). Factors impacting food workers' and managers' safe food preparation practices, a qualitative study introduction. Journal of Food Protection, 25(12), 981-990.

Fraser Health Authority (FHA). (2011). Inspection reports. Retrieved from: http://www.fraserhealth.ca/your_environment/f ood_safety/inspection_reports/

Fraser Health. (2013). EHS programs \& services. (C) Health Protection, Fraser Health Authority. Retrieved from http://www.healthspace.ca/Clients/FHA/FH A_Website.nsf/Env-Frameset

Fraser Health Authority (FHA). (2014). Food premise facilities. Retrieved from: http://www.healthspace.ca/fha/food

Heacock, H., Sidhu, B. (2013) Research methods module 5: descriptive statistics. BCIT ENVH 8400- Research Methods Course Notes.

Hedberg, C. W., Smith, S. J. A. Y., Kirkland, E., Radke, V., Jones, T. I. M. F., Selman, C. A., \& Group, T. H. E. E. W. (2006). Systematic environmental evaluations to identify food safety differences between outbreak and nonotbreak restaurants. Journal of Food Protection, 69(11), 2697-2702.

Jones, T. F., Pavlin, B. I., LaFleur, B. J., Ingram, L. A., \& Schaffner, W. (2004). Restaurant inspection scores and foodborne disease. 
Emerging Infectious Diseases, 10(4), 688-92. doi:10.3201/eid1004.030343

Liu, P., \& Kwon, J. (2013). The exploration of effects of Chinese cultural values on the attitudes and behaviors of Chinese restaurateurs toward food safety training. Journal of Environmental Health, 75(10), 38-46. Retrieved from http://www.ncbi.nlm.nih.gov/pubmed/2385866 4

Mauer, W. a, Kaneene, J. B., DeArman, V. T., Roberts, C. a, Miller, R., Pong, L., \& Dickey, T. E. (2006). Ethnic-food safety concerns: an online survey of food safety professionals. Journal of Environmental Health, 68(10), 328. Retrieved from http://www.ncbi.nlm.nih.gov/pubmed/1677999 9

Microsoft Office Professional Plus. (2013). Microsoft Excel (Version 2013). Microsoft Corporation.

Newbold, K. B., McKeary, M., Hart, R., \& Hall, R. (2008). Restaurant inspection frequency and food safety compliance. Journal of Environmental Health, 71(4), 56-61. Retrieved from

http://www.ncbi.nlm.nih.gov/pubmed/1900439 6

NCSS: Statistical \& Power Analysis Software. (2007). Accessed November 14, 2013. Website: http://www.ncss.com/

Pham, M., \& Jones, A. (2012). Food safety issues and information needs : An online survey of public health inspectors. Journal of Environmental Health, (June), 22-30. Retrieved from http://www.ncbi.nlm.nih.gov/pubmed/2270820 4

Public Health Agency of Canada (PHAC). 2010. Canada's food-borne illness outbreak response protocol (FIORP) 2010: to guide a multijurisdictional response. Retrieved from http://www.phac-aspc.gc.ca/zoono/fiorpmitioa/index-eng.php\#toc1

Public Health Agency of Canada (PHAC). 2013. Estimates of food-borne illness in Canada. Retrieved from http://www.phacaspc.gc.ca/efwd-emoha/efbi-emoa-eng.php
Roberts, K., Kwon, J., Shanklin, C., Liu, P., \& Yen, W.-S. (2011). Food Safety Practices Lacking in Independent Ethnic Restaurants. Journal of Culinary Science \& Technology, 9(1), 1-16. doi:10.1080/15428052.2011.549041

Simonne, A., \& Nille, A. (2004). Ethnic food safety trends in the United States based on CDC foodborne illness data Food Protection Trends, 24(8), 590-604. Retrieved from http://www.researchgate.net/publication/23590 0696_Ethnic_food_safety_trends_in_the_Unite d_States_based_on_CDC_foodborne_illness_d ata/file/3deec516ee4bd0b9e6.pdf

Sharkey, K. W., Alam, M., Mase, W., \& Ying, J. (2012). An investigation to determine association between foodborne illness and number of citations in a food establishment. Journal of environmental health, 75(2), 8-11. Retrieved from http://www.ncbi.nlm.nih.gov/pubmed/2298472 9

Statistics Canada. 2012. Section 1: food in Canada. Retrieved from http://www.statcan.gc.ca/pub/16-201x/2009000/part-partie1-eng.htm

Thomas, M. K., Murray, R., Flockhart, L., Pintar, K., Pollari, F., Fazil, A., Marshall, B. (2013). Estimates of the burden of foodborne illness in Canada for 30 specified pathogens and unspecified agents, circa 2006. Foodborne Pathogens and Disease, 10(7), 639-48. doi:10.1089/fpd.2012.1389

Waters, a B., VanDerslice, J., Porucznik, C. a, Kim, J., DeLegge, R., \& Durrant, L. (2013). Impact of internet posting of restaurant inspection scores on critical violations. Journal of Environmental Health, 75(10), 8-12. Retrieved from http://www.ncbi.nlm.nih.gov/pubmed/2385866 1

Yelp. (2013). @ 0 2004-2013 Yelp. Retrieved from www.yelp.ca.

Yeager, V. a, Menachemi, N., Braden, B., Taylor, D. M., Manzella, B., \& Ouimet, C. (2012). Relationship between food safety and critical violations on restaurant inspections: an empirical investigation of bacterial pathogen 
content. Journal of Environmental Health, 75(6), 68-73. Retrieved from

http://www.ncbi.nlm.nih.gov/pubmed/2339765

2 